
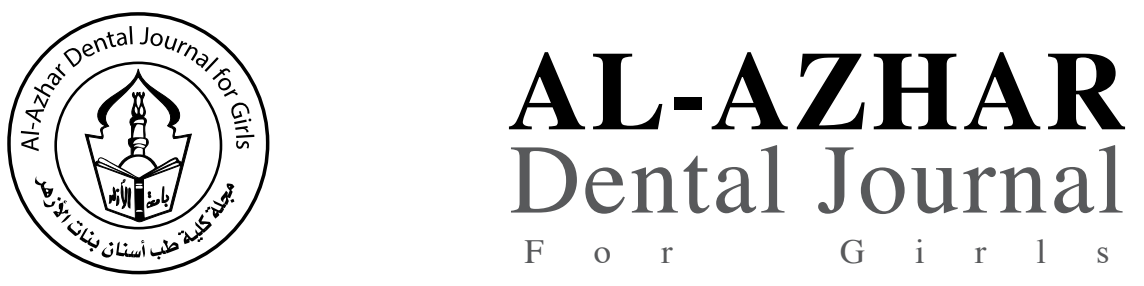

The Official Publication of The Faculty of Dental Medicine For Girls, Al-Azhar University Cairo, Egypt.

ADJ-for Grils, Vol. 3, No. 2, April (2016) - PP. 135:140

\title{
Evaluation of The Antimicrobial Effect of Propolis Extract on Oral Microflora
}

\author{
Safaa Ramadan El-sayed ${ }^{(1)}$, Samy Yossef El-Bayoumy ${ }^{(2)}$, Mohamed Hassan Mostafa $^{(3)}$ \\ and Magda Ahmed EL-Malt ${ }^{(4)}$
}

Codex : 07/1604

dentaljournal.forgirls@yahoo.com

\section{ABSTRACT}

Aim: This study was conducted to evaluate the antimicrobial effect of propolis extract with different dilutions when applied as mouth wash in vivo against a known antiseptic agent $(0.2 \%$ Chlorhexidine $)$.

Material and Methods: Ninety children were selected for this study. All children were examined clinically for dental caries and used to evaluate the antimicrobial effect of studied materials. The childern were divided equally into two groups (fourty five in every group). In the first group childern were instructed to rinse with $3 \mathrm{ml}$ of propolis extract for specific time and divided into three sub groubs while in the other group childern were instructed to rinse with $3 \mathrm{ml}$ of Chlorhexidine.

Result: The results of this study revealed that the use of propolis mouth wash by childern achieved mean of reduction of total bacterial count. The effect of $0.2 \%$ Chlorhexidine was higher than the effect of propolis in total bacterial count reduction

Conclusion: This study concluded that Propolis is an antimicrobial agent as it significantly reduced the total bacterial count in the saliva of childern when compared by apotent antiseptic like $0.2 \%$ chlorhexidine.

\section{INTRODUCTION}

Dental caries(decay) is one of the most prevalent chronic childhood diseases worldwide and is a major problem both from a population health perspective and for individual families who have to deal with

1. Demonstrator at Pedodontics and Oral Dental Health, Faculty of Dental Medicine (Girl's Branch), Al-Azhar University

2. Professor and Head of Department of Pedodontic and Dental Puplic Health, Faculty of Dental Medicine (Boy's Branch), Al-Azhar University

3. Associate Professor and Head of Department of Pedodontic and Dental Puplic Health, Faculty of Dental Medicine (Girl's Branch), Al-Azhar University

4. Lecturer of Pedodontics and Oral Dental Health,Faculty of Dental Medicine (Girl's Branch), Al-Azhar University 
a younge child suffering from toothache ${ }^{(1)}$. It is characterized by colonization and accumulation of oral microorganisms on dental surfaces, resulting in the formation of dental plaque and demineralization of the tooth structure. Therefore, control of the bacterial biofilm on teeth is essential for the maintenance of oral health.Some antiseptics,such chlorhexidine and triclosan, have been used in cariology ${ }^{(2)}$

Antiseptic mouth rinse solutions are used for improvement of the dental health (plaque and gingivitis elimination in particular) and prevention of infection caused by bacteria of the oral cavity in specific situation such as tooth extraction ,intraoral surgical procedures or immune suppression due to cancer therapy or transplantation. The use of antimicrobial mouth rinses have been proposed as a mean of reducing the level of oral bacteria ${ }^{(3)}$.

There are many other natural compounds like xylitol, green tea,mint and Propolis that had been applied as mouth rinses to reduce oral bacteria. Bees and dentists have a few things in common. They are both hardworking, industrious and have a capacity to cause a great deal of discomfort and pain. However, the power and ability to heal is also some thing we dentists have in common with our little winged friends too. Propolis, is derived from the Greek pro - 'for or in defence of' and polis - 'the city', hence, 'defender of the city/hive'. Propolis is a naturally-occurring bee product. It is a hard resinous substance consisting chiefly of wax and plant extracts ${ }^{(4)}$

Propolis contains proteins, amino acids, vitamins, minerals, and flavonoids. Preparations with propolis have been found to be antimicrobial, anti-inflammatory, have antiscar effects, and to be highly antimycotic. ${ }^{(5)}$

\section{MATERIALS AND METHODS}

A total of ninety Egyptian children from both sexes were included in this study.Ethical approval was obtained from the Research and Ethics committee of the Faculty of Dental Medicine of
Al-Azhar University (Girls Branch), Cairo, Egypt . The study was explained to all participants' parents and they signed informed consent denoting their agreement to participate in the study . Also verbal consent from the children was obtained.All children were examined clinically for dental caries using sterile diagnostic set including:plane mirror, sickle explorers and tweezers. The children were selected fulfilling the inclusion criteria;-

- Their age ranged from( 5-12 year)

- Systemically healthy patients.

- Absence of any fixed or removable orthodontic appliances or prosthesis.

- No untreated cavities

- No history of any anti-microbial mouth wash several hours before sample collection

- No history of recent antibiotic therapy

- No change in dietary habits and day to day practices

\section{Preparation of propolis mouth wash}

Propolis extract $(3 \mathrm{ml}, 5 \mathrm{ml}$, and $10 \mathrm{ml})$ diluted in $90 \mathrm{ml}$ sterile water and placed in a hermatically sealed bottles and kept at room tempreture.

\section{Grouping of childern}

The childern randomly distributed into two groups each of 45 (group Aand B).

\section{Group A (experimental group):}

Forty five subjects were instructed to rinse with $3 \mathrm{ml}$ of propolis extract for 5 days three times a day and divided into three sub groups;

Sub group1: Childern were instructed to rinse their mouth with $3 \mathrm{ml}$ of $(10 \mathrm{ml}$ of propolis extract diluted in $90 \mathrm{ml}$ sterile water) for 1 minute three times a day for 5 days under their parent's supervision. 
$>$ Sub group 2: Childern were instructed to rinse their mouth with $3 \mathrm{ml}$ of $(5 \mathrm{ml}$ of propolis extract diluted in $90 \mathrm{ml}$ sterile water) for 1 minute three times a day for 5 days under their parent's supervision.

Sub group3: Childern were instructed to rinse their mouth with $3 \mathrm{ml}$ of ( $3 \mathrm{ml}$ of propolis extract diluted in $90 \mathrm{ml}$ sterile water) for 1 minute three times a day for 5 days under their parent's supervision.

\section{Group B (control group):}

45 subjects were instructed to rinse with $3 \mathrm{ml}$ of chlorhexidine for 1 minute ,three times for 5 days under their parent's supervision.

\section{Collection of sample}

Saliva samples were collected from each child by asking him to spit in a labeled sterile container(3 $\mathrm{ml}$ on the average). Each subject was refrained from tooth brushing in the morning and from eating or drinking at least 1hours before sampling time

Baseline sample $\left(\mathbf{S}_{\mathbf{1}}\right)$ : The initial sample was taken before using the mouth wash by asking the child to spit in a labeled sterile container ( $3 \mathrm{ml}$ on the average).

Second sample $\left(\mathbf{S}_{2}\right)$ : The second sample was taken after using specific mouth wash for 5 days by asking the child to spit in a labeled sterile container ( $3 \mathrm{ml}$ on the average). Procedures of sampling occurred in complete aseptic conditions because any contamination could affect the bacteriological counts

\section{Microbiological analysis for total microbial count:}

All collected saliva samples from each group were immediately submitted to the Culture and Sensitivity Unit at Regional Center for Mycology and Biotechnology at Al-azhar University.
The saliva sample( $3 \mathrm{ml}$ on the average) was diluted at (1:100 and 1:1000).For each dilution (20 microliters) of the sample was taken by micropipette from the sterile container.

After dilution,the sample was inoculated in plate count agar media(Also known as: Trypticase Glucose Yeast Agar; Standard Methods Agar). Each sample was cultured in triplicate. The plates were incubated at $37 \mathrm{C}$ for $24-48$ hours $^{(6)}$.

After the incubation period passed,colony forming units of saliva sample was determined by using the number of colonies in agiven dilution.

\section{Statistical analysis}

- Analysis of data was performed using SPSS 17 (Statistical Package for Scientific Studies) for Windows

- Description of quantitative variables was in the form of mean, standard deviation (SD). Data were explored for normality using KolmogorovSmirnov test of normality. The results of Kolmogorov-Smirnov test indicated that most of data were normally distributed (parametric data) so parametric tests were used for the comparisons.

- Different treatments were compared using analysis of variance (ANOVA) test, followed by Tukey's post hoc test when a significant difference was detected. In each treatment, the significance of the difference between the baseline values of total bacterial count and values after treatment was calculated using Student's $t$ test.

- Results were expressed in the form p-values that were differentiated into:

\footnotetext{
* Non-significant when p-value $>0.05$

* Significant when p-value $\leq 0.05$
} 


\section{RESULTS}

\section{1- Bacterial count (C.F.U.) at baseline}

Total bacterial count was calculated as colony forming unit (C.F. U.). The mean value at baseline (before treatment) didn't significantly differ between groups. ANOVA test revealed a $\mathrm{p}$ value $=0.965$

\section{2- Bacterial count (C.F.U.) after treatment}

Total bacterial count was calculated as colony forming unit (C.F. U.). The mean value after treatment showed the lowest value in the chlorohexidine group $(2405 \pm 509)$. The greatest value was observed in the Propolis $-3 \mathrm{ml}$ group $(1,078,867 \pm 302,179)$. ANOVA test revealed a significant difference ( $p<0.00001$ ) between the different groups. Tukey's post hoc test revealed a significant difference between each two groups.

Table 1. Total bacterial count (C.F.U.) at baseline before treatment (S1) and significance of the difference using ANOVA test

\begin{tabular}{|c|c|c|c|c|}
\hline & \multicolumn{3}{|c|}{ Test group Group A } & Control group Group B \\
\hline & $\begin{array}{c}\text { Sub group (1) } \\
\text { Propolis- 10ml }\end{array}$ & $\begin{array}{c}\text { Sub group (2) } \\
\text { Propolis- 5ml }\end{array}$ & $\begin{array}{c}\text { Sub group (3) } \\
\text { Propolis- 3ml }\end{array}$ & Chlorohexidine \\
\hline Mean & $27,680,000$ & $28,160,000$ & $27,400,000$ & $26,640,000$ \\
\hline SD & $3,648,718$ & $5,616,913$ & $10,734,723$ & $10,352,143$ \\
\hline P value & & \multicolumn{2}{|c|}{$0.965^{\text {ns }}$} \\
\hline
\end{tabular}

ns=non-significant

Table 2. Total bacterial count (C.F.U.) after treatment (S2) and significance of the difference using ANOVA test

\begin{tabular}{|c|c|c|c|c|}
\hline & \multicolumn{3}{|c|}{ Test group Group A } & Control group Group B \\
\hline & $\begin{array}{c}\text { Sub group (1) } \\
\text { Propolis- 10ml }\end{array}$ & $\begin{array}{c}\text { Sub group (2) } \\
\text { Propolis- 5ml }\end{array}$ & $\begin{array}{c}\text { Sub group (3) } \\
\text { Propolis- 3ml }\end{array}$ & Chlohexidine \\
\hline Mean & $6,753^{\mathrm{a}}$ & $364,000^{\mathrm{b}}$ & $1,078,867^{\mathrm{c}}$ & $2,405^{\mathrm{d}}$ \\
\hline SD & 1,267 & 63,336 & 302,179 & 509 \\
\hline F value & \multicolumn{3}{|c|}{186.3} \\
\hline P value & \multicolumn{3}{|c|}{$<0.00001^{*}$} \\
\hline
\end{tabular}

* Statistically significant

Tukey's post hoc test: means with different superscript letters are significantly different

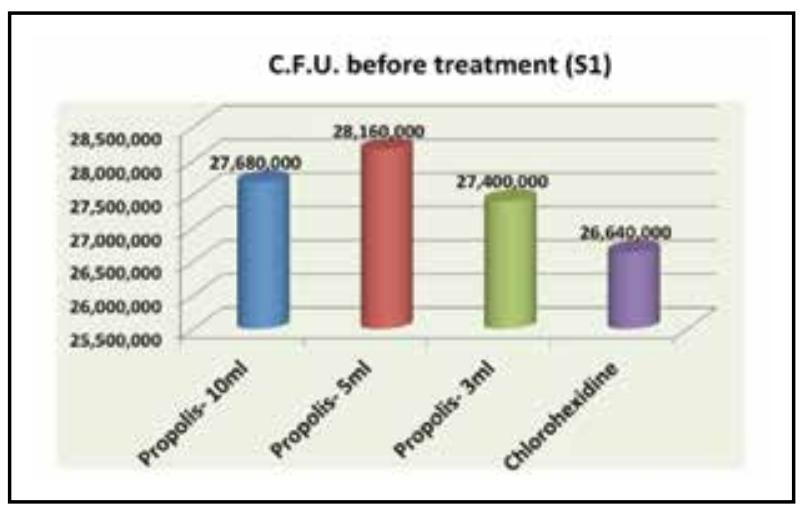

Fig. (1) Column chart showing mean total bacterial count (C.F.U.) at baseline before treatment (S1)

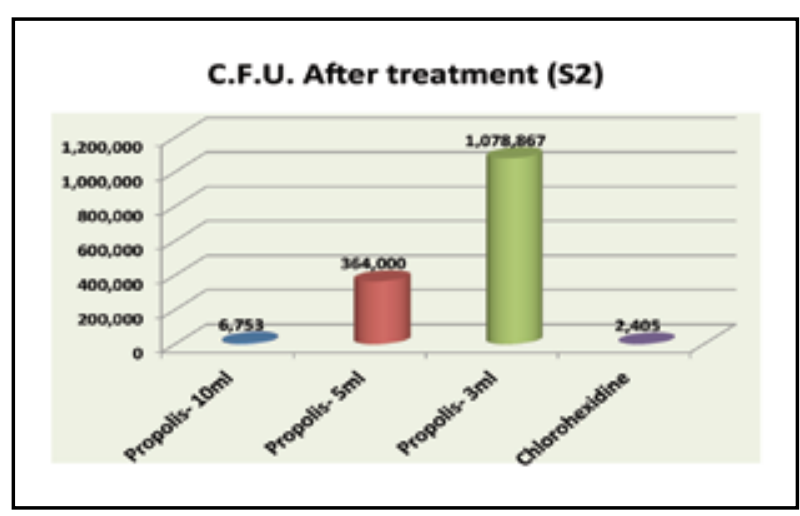

Fig. (2) Column chart showing mean total bacterial count (C.F.U.) after treatment 


\section{DISCUSSION}

Oral diseases persist to be a major health problem around the world ${ }^{(7)}$. Apart from dental caries and periodontal diseases which are the most important global oral health problems, other conditions like oral and pharyngeal cancers and oral tissue lesions are also of important concern. Oral health is essential to general well-being and is related to the quality of life that extends beyond the functioning of the craniofacial complex. The relationship between oral diseases and activities of the microbiota of the oral cavity is well established. Over 750 species of bacteria (50\% of which are still to be identified) colonize the oral cavity and a number of these are responsible in oral diseases.The world wide need for alternative treatment and preventive options and products for oral diseases that are effective, safe and economical comes from the rise in disease incidence, increased resistance by pathogenic bacteria to currently used antibiotics ${ }^{(8)}$.

The application of natural agents with antimicrobial activities on dental surfaces promotes a reduction in biofilm formation. In addition, these agents can inhibit bacterial colonization, growth, and metabolism ${ }^{(9)}$.

In this study we used propolis as it is safe and natural. It is a non toxic substance and for most people, will not cause irritation when used as supplements or applied to the skin.Propolis allergy upon ingestion seems to be less frequent than contact allergy, is probably due to its anti-allergenic and anti-inflammatory effects ${ }^{(\mathbf{1 0})}$.

In the present study the children ages (5-12) were decided as they can easily rinse their mouth without swallowing the mouthwash to avoid swallowing reflex. This is in agreement with ${ }^{(1)}$ who suggested that mouth rinses should be recommended only for those children who have demonstrated mastery of their swallowing reflex.

In this study distilled water was used for preparation of mouth rinses as alcohol used in oral care products can be irritating to the cheeks, teeth and gums. Excessive use of products that contain alcohol may also weaken the immune system's natural ability to fight bacteria and illness ${ }^{(12)}$.

In our study, after the use of propolis mouth wash by childern resulted in ahighly significant for total bacterial count $(\mathrm{P}<0.05)$. This agreed with a study (13) which proved that propolis had antimicrobial effect on salivary bacterial count .

The results of this study was supported by several studies ${ }^{(14,15)}$ which studied antimicrobial effect of propolis on various oral microorganism and found that propolis had greater effect on oral bacteria and evaluated the antibacterial action of an extract of propolis on the concentration of Streptococcus mutans colonizing the oral cavity of young patients. They concluded that propolis extract possesses in vivo antimicrobial activity against $\mathrm{S}$. mutans present in the oral cavity and might be used as an alternative measure to prevent dental caries

This study also agreed with previous studies that ${ }^{(4,16)}$ who concluded that propolis is very effective on oral pathogenic microorganisms (such as Streptococcus mutants, Candida albicans and Actinobacillus a. commitans) and concluded that propolis might be used as a natural mouthwash,an alternative to chemical mouthwashes, e.g., chlorhexidine.

In the present study, we used 3 concentration of propolis $(10 \mathrm{ml}, 5 \mathrm{ml}, 3 \mathrm{~m})$ diluted in $90 \mathrm{ml}$ sterial water, the least mean of the total bacterial count was related to the greatest concentration (propolis $10 \mathrm{ml}$ ) and gradually increased in the more diluted solution. The greatest value was observed in the (propolis $3 \mathrm{ml}$ ) and significant difference $(\mathrm{p}<0.001)$ between the different groups. This agreed with a study ${ }^{(17)}$ who found that the antimicrobial activity of propolis depending on propolis sample, dosage of propolis and increased with increasing dosage without reaching the highest dosage tested.

In the present study, we used (0.02\%) chlorhexidine mouth wash as control group and showed highly significant reduction $(\mathrm{p}<0.05)$ for the total oral bacteria these results were agreed with a study ${ }^{(18)}$ who compared the antimicrobial efficacy 
of $0.2 \%$ chlorhexidine mouth rinse and mouth rinse containing $0.03 \%$ triclosan, $0.05 \%$ sodium fluoride, and 5\% xylitol in reducing the streptococcus mutans count in plaque. Statistically significant reduction in the streptococcus mutans count in the plaque was seen in the control and study group from baseline level. But when both the groups were compared, the antimicrobial effect of chlorhexidine was more than the propolis group.

To conclude all our results, there was insignificant difference between the results of all tested groups before using the mouth washes (propolis and chlorhexidine) but there was significant difference $(p<0.00001)$ between these groups after using the mouth washes. The mean value after treatment showed the lowest value in the chlorhexidine group. The greatest value was observed in the propolis (3ml) group.

\section{CONCLUSION}

1. Propolis is safe and natural. It is a non toxic substance and not caused allregy upon ingestion due to its anti-allergeic and anti-inflammatory effects, due to the flavonoids

2. Propolis is an antimicrobial agent as it significantly reduced the total bacterial count in the saliva of childern when compared by apotent antiseptic like $0.2 \%$ chlorhexidine

3. Propolis is a subject of recent dentistry research due to it's antimicrobial properties, it has been called a *natural antibiotic*

\section{REFERENCES}

1. Chu CH,Fung DSH, and Lo ECM: Dental caries status of preschool children in Hong Kong.British Dental Journal. (1999),187:616-20.

2. Bouwsma OJ:The status, future and problems of oral antiseptics.Curr Opin Periodontal Journal (1996); (3)78-84.

3. Cannell JS.The use of antimicrobials in the mouth. Journal of International Medical Research (1981);9:277-82

4. Dodwad and Bhavna JK;Propolis mouthwash: A new beginning;Journal of Indian Society of Periodontology (2011) Apr-Jun; 15(2): 121-125.
5. Silveira MG, Gou-Godoy A.,Torriente OR, Palmer-Ortiz MC., and Falcón-Cuéllar MA.,;- Preliminary study of the effects of propolis in the treatment of chronic gingivitis and oral ulceration. Revista Cubanade Estomatología Journal's. (1998);25:36-44.

6. Atlas RM,:-.Handbook of Microbiological Media.London: CRC Press. pp. p. 1390. ISBN 0-8493-1818-1.(2004)

7. Petersen PE., Bourgeois D, Ogawa H, Estupinan DS, and Ndiaye C.: The global burden of oral diseases and risks to oral health. Bulletin of the World Health Organization Journal(2005); 83(9): 661-69.

8. Jenkinson HF and LamontRJ.;-Oral microbial communities in sickness and in health. Trends in MicrobiologyJournal. (2005); 13(12):589-95.

9. Selwitz R., Ismail A., and Pitts N., Dental caries. Lancet Journal (2007);369(9555):51-59.

10. Parolia A, Thomas S, Kundabala $M$ and Mohan M .Propolis and its potential uses in oral health. Int. J. Med. Med. Sci. (2010); 2(7):210-215.

11. Adair SM.: Evidence-based use of fluoride in contemporary pediatric dental practice.Journal of Pediatric Dentistry; (2006); 28:133-42.

12. Romeo J, Warnberg J, Nova E, Diaz LE, Gomez-Martinez $\mathrm{S}$ and Marcos A. Moderate alcohol consumption and the immune system: a review. Br J Nutr. 2007;98:111-5.

13. Steinberg D., and Gedalia KG.,:- Antibacterial effect of propolis and honey on oral bacteria. American journal of dentistry (1996);9:236-8.

14. Stuart .T,;- Effect Of Propolis-Based Antimicrobial On Oral Bacteria; University Of Tennessee,Science Center, Memphis, Tn March , (2012).

15. Mohsin S, Manohar B, Rajesh S, and Asif Y;- The ffects of a dentifrice containing propolis on mutans streptococci: a clinico-microbiological study. Ethiopian Journal of Health .January(2015) 25 (1) 9-16.

16. Moumen BEJ,.Mansourian A., Masoumeh ,Amanlou M. Mohammadnia AAR. And Naghmeh B ;-Antimicrobial effects of propolis extract on the most prevalent oral pathogens: an in vitro study; Majallah-i-Dandanpizishki Journal ( 2009 ), 21(1 ) 33- 39.

17. Ugur A and Arslan T.;-An in vitro study on antimicrobial activity of propolis from Mugla province of Turkey.Journal of Medicinal Food,(2004) 9;(7)90-4

18. Lakade LS., Shah P,and Shirol D. ;Comparison of antimicrobial efficacy of chlorhexidine and combination mouth rinse in reducing the mutans streptococcus count in plaque.Journal of Indian Society of Pedodontics and Preventive Dentistry. (2014);32:91-6. 